\title{
INVESTIGATING THE PEDAGOGY OF MATHEMATICS
}

How Do Teachers Develop Their Knowledge? 
This page intentionally left blank 


\section{INVESTIGATING THE PEDAGOGY OF MATHEMATICS How Do Teachers Develop Their Knowledge?}

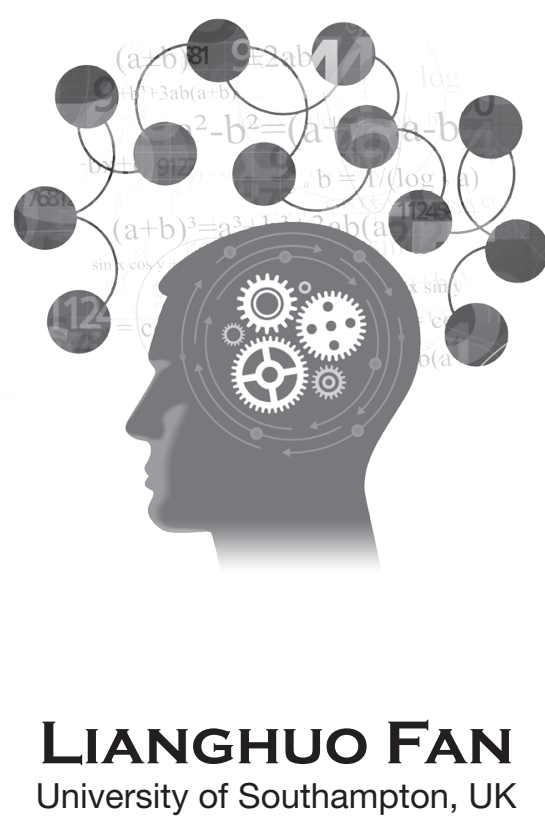

\section{LIANGHUO FAN \\ University of Southampton, UK}




\section{Published by}

Imperial College Press

57 Shelton Street

Covent Garden

London WC2H 9HE

\section{Distributed by}

World Scientific Publishing Co. Pte. Ltd.

5 Toh Tuck Link, Singapore 596224

USA office: 27 Warren Street, Suite 401-402, Hackensack, NJ 07601

UK office: 57 Shelton Street, Covent Garden, London WC2H 9HE

\section{Library of Congress Cataloging-in-Publication Data}

Fan, Lianghuo.

Investigating the pedagogy of mathematics : how do teachers develop their knowledge? /

Lianghuo Fan, University of Southampton, UK.

pages $\mathrm{cm}$

Includes bibliographical references and index.

ISBN 978-1-78326-457-5 (hardcover : alk. paper)

1. Mathematics teachers--Training of--Research. 2. Teachers--Training of--Research. I. Title.

II. Title: How do teachers develop their knowledge?

QA11.2.F36 2014

510.71--dc23

2014019239

\section{British Library Cataloguing-in-Publication Data}

A catalogue record for this book is available from the British Library.

\section{Copyright (C) 2014 by Imperial College Press}

All rights reserved. This book, or parts thereof, may not be reproduced in any form or by any means, electronic or mechanical, including photocopying, recording or any information storage and retrieval system now known or to be invented, without written permission from the Publisher.

For photocopying of material in this volume, please pay a copying fee through the Copyright Clearance Center, Inc., 222 Rosewood Drive, Danvers, MA 01923, USA. In this case permission to photocopy is not required from the publisher.

Typeset by Stallion Press

Email: enquiries@stallionpress.com 


\section{Contents}

List of Figures $\quad$ ix

List of Tables $\quad x i$

Focusing on the Growth of Teachers' Knowledge: An Introduction xix

Part I The Chicago Study 1

Chapter 1 Introduction 3

Background of the Chicago Study . . . . . . . . . 3

Need for the Study . . . . . . . . . . . . . . . . 4

Statement of the Problem .............. 5

Structure of Part I . . . . . . . . . . . 6

Chapter 2 Review of the Literature 9

What is Knowledge? . . . . . . . . . . . . 10

What Knowledge do Teachers Need? . . . . . . . 16

What Knowledge do Teachers Have? . . . . . . . 25

How do Teachers Develop their Knowledge? . . . 29

Summary of the Review . . . . . . . . . . 36

Chapter 3 A Conceptual Framework of the Study 37

Knowledge ..................... 37

Teachers' Knowledge . . . . . . . . . 42 
Teachers' Pedagogical Knowledge . . . . . . . . . 44

Sources of Teachers' Pedagogical Knowledge . . . 49

Summary ................. 54

Chapter 4 Research Design and Procedures 57

Population and Sample . . . . . . . . . . . . . . . . 57

Instruments . . . . . . . . . . . . . . . 59

Data Collection ................. 64

Data Processing and Analysis . . . . . . . . . . 68

Strengths and Limitations of the Methodology . . . . . . . . . . . . . . 71

Summary of the Methodology . . . . . . . . 72

Chapter 5 Findings of the Chicago Study (I): Pedagogical

Curricular Knowledge $\quad 75$

Knowledge of Teaching Materials . . . . . . . . . . 76

Knowledge of Technology . . . . . . . . . . . . . . . . 92

Knowledge of Other Teaching Resources . . . . . 106

Summary of the Findings . . . . . . . . . . 116

Chapter 6 Findings of the Chicago Study (II):

Pedagogical Content Knowledge 119

Analysis of the Questionnaire Data . . . . . . . 121

Analysis of the Interview Data . . . . . . . . . . . 130

Summary of the Findings . . . . . . . . . . 152

Chapter 7 Findings of the Chicago Study (III):

Pedagogical Instructional Knowledge 155

Analysis of the Questionnaire Data . . . . . . . . . 156

Analysis of the Interview Data . . . . . . . . . . . 160

Summary of the Findings . . . . . . . . . . 183

Chapter 8 Findings of the Chicago Study (IV):

Some Other Issues 185

How Teachers Use Different Sources . . . . . . . 186 
How Teachers Improve their Pedagogical

Knowledge ............... 201

Summary of the Findings . . . . . . . . 205

Chapter 9 Conclusions, Implications, and Recommendations 209

Summary and Conclusions . . . . . . . . . . . 209

Implications for Teacher Educators, School

Administrators, and Teachers . . . . . . . 213

Recommendations for Further Study . . . . . . 216

$\begin{array}{ll}\text { Part II The Singapore Study } & 219\end{array}$

$\begin{array}{lll}\text { Chapter } 10 & \text { The Singapore Study } & 221\end{array}$

Background and Introduction of the Singapore Study . . . . . . . . . . 221

The Conceptual Framework . . . . . . . . . 226

Methodological Matters . . . . . . . . . 230

Findings of the Singapore Study . . . . . . . . . . . 235

Summary of the Singapore Study . . . . . . . . 257

$\begin{array}{lll}\text { Chapter } 11 \text { Comparison and Conclusion } & 261\end{array}$

Comparison of the Chicago and Singapore Studies . . . . . . . . . . 261

Concluding Remarks . . . . . . . . . . . . 269

Appendix 1A Teacher Questionnaire (Chicago Study) 275

Appendix 1B Notes for Classroom Observation 287

Appendix 1C Script for Interviewing Teachers 289

Appendix 1D Script for Interviewing Math Chairs 293

Appendix 1E A Profile of Teacher Participants (Chicago Study) 295

Appendix 1F Main Results of Logistic Regression

Analyses (Chicago Study)

Pedagogical Curricular Knowledge - Knowledge of Textbooks . . . . . . . . . . . . . 
Pedagogical Curricular Knowledge - Knowledge of Technology . . . . . . . . . . . . . 300

Pedagogical Curricular Knowledge - Knowledge of Concrete Materials . . . . . . . . . . 301

Pedagogical Instructional Knowledge . . . . . . 302 Knowledge Sources Used to Represent New Topics . . . . . . . . . . . . . . . 303

Pedagogical Content Knowledge . . . . . . 303

Appendix 2A A Profile of Teacher Participants (Singapore Study) 305

Appendix 2B Teacher Questionnaire (Singapore Study) 307

References $\quad 321$

Author Index $\quad 333$

$\begin{array}{ll}\text { Subject Index } & 337\end{array}$ 


\section{List of Figures}

2.1 Three types of knowledge for mathematics teachers by Lappan and Theule-Lubienski (1994) . . . . . . . . 20

3.1 A framework to investigate the sources of teachers' pedagogical knowledge . . . . . . . . . . . . 51

$5.1 \quad$ Knowledge of textbooks being used . . . . . . . . 77

5.2 Comparison of the contribution of different sources to teachers' knowledge of textbooks . . . . . . . . . 79

5.3 Comparison of the three groups of teachers' average evaluation of the contribution of different sources to their knowledge of textbooks . . . . . . . . .

5.4 Comparison of the contribution of different sources to teachers' knowledge of technology . . . . . . .

5.5 Comparison of the three groups of teachers' average evaluation of the contribution of different sources to teachers' knowledge of technology . . . . . . . . .

5.6 Comparison of the contribution of different sources to teachers' knowledge of concrete materials . . . . . .

5.7 Comparison of the three groups of teachers' average evaluation of the contribution of different sources to teachers' knowledge of concrete materials . . . . . .

6.1 Proportions of teachers who got their PCnK about various topics from different sources . . . . . . . . 126

7.1 Comparison of the contribution of different sources to teachers' PIK . . . . . . . . . . . . . 
7.2 Comparison of the three groups of teachers' average evaluations of the contribution of different sources to their PIK . . . . . . . . . . . . . . 160

8.1 Percentages of teachers who were taught different pedagogical knowledge in their preservice training . . . . . . . . . . . . . 190

10.1 A framework to investigate the sources of Singaporean teachers' pedagogical knowledge . . . . . . . . . 228

10.2 Percentage of the Singaporean teachers who got their $\mathrm{PCnK}$ about various topics they listed from different sources . . . . . . . . . . . 250 


\section{List of Tables}

4.1 Distribution of the questions in the questionnaire in terms of the components of teachers' pedagogical knowledge and the knowledge sources . . . . . . . . . . 60

4.2 Numbers of students, teachers, and mathematics teachers in the three sample schools (1996-1997) . . . . . . . 65

4.3 Response rate of the questionnaire survey . . . . . . . 65

4.4 Selection of teachers for classroom observation . . . . 66

4.5 Classes observed for the study . . . . . . . . . . . . . 67

5.1 Courses taught by teachers . . . . . . . . . 77

5.2 Distributions of the numbers of teachers giving different evaluations about the contribution of various sources to the development of their knowledge of textbooks . . . . . . . . . . . . .

5.3 Distributions of the numbers of teachers among the three groups giving different evaluations of the contribution of each source to their knowledge of textbooks . . . .

5.4 Sources of teachers' knowledge of textbooks (from interview data) . . . . . . . . . . .

5.5 How often teachers used calculators and computers in their mathematics classes . . . . . . . . . . . .

5.6 Distributions of the numbers of teachers giving different evaluation about the contribution of various sources to the development of their knowledge of how to use technology for teaching mathematics ....... 
5.7 Distributions of the numbers of teachers among the three groups giving different evaluations of the contribution of each source to their knowledge of technology . . . . . . . . .

5.8 Sources of teachers' knowledge of technology (from interview data) . . . . . . . . . . . .

5.9 How often teachers used concrete materials to teach mathematics . . . . . . . . . . . . . .

5.10 Distributions of the numbers of teachers giving different evaluations about the contribution of various sources to their knowledge of concrete materials . . . . . . . .

5.11 Distributions of the numbers of teachers among the three groups giving different evaluations of the contribution of each source to their knowledge of concrete materials

5.12 Sources of teachers' knowledge of concrete materials (from the interview data) . . . . . . . . . . .

5.13 A summary of the importance of different sources to the development of teachers' $\mathrm{PCrK}$. . . . . . . .

6.1 Distributions of the mathematics topics given by teachers in Questions 20 and $21 \ldots \ldots$. . . . . . . .

6.2 Sources of teachers' $\mathrm{PCnK}$ reported in the questionnaire

6.3 Numbers of teachers who answered the questions among the three groups . . . . . . . . . .

6.4 Teachers' responses across the three groups about the sources of their PCnK of the topics given in Questions 20 and 21 . . . . . . . . . . .

6.5 Teachers' responses across the three groups to the questions of their developing their PCnK from Source E . . . . .

6.6 Sources of teachers' PCnK (from interview data) . . . .

7.1 Distributions of the numbers of teachers giving different evaluations about the contributions of various sources to their PIK . . . . . . . . . . . . . . . . 
7.2 Distributions of the numbers of teachers among the three groups giving different evaluations of the contribution of each source to their PIK . . . . . . . . . . . . .

7.3 Teaching strategies and the knowledge sources

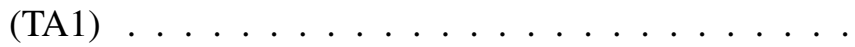

7.4 Teaching strategies and the knowledge sources

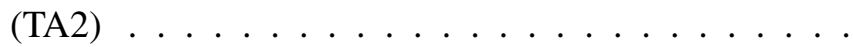

7.5 Teaching strategies and the knowledge sources

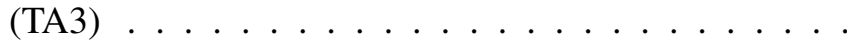

7.6 Teaching strategies and the knowledge sources (TB1) . . . . . . . . . . . . . . .

7.7 Teaching strategies and the knowledge sources (TB2) . . . . . . . . . . . . . . . . 174

7.8 Teaching strategies and the knowledge sources (TB3) . . . . . . . . . . . . . .

7.9 Teaching strategies and the knowledge sources (TC1) . . . . . . . . . . . . .

7.10 Teaching strategies and the knowledge sources (TC2) . . . . . . . . . . . .

7.11 Teaching strategies and the knowledge sources (TC3)

7.12 Sources of teachers' PIK (from interview data)

8.1 Teaching strategies used as teachers and encountered as students, reported by teachers . . . . . . . . . .

8.2 Teachers' evaluation of the usefulness of preservice training courses in enhancing their pedagogical knowledge .................

8.3 Courses taken by teachers in non-degree professional training

8.4 Distribution of the majors teachers enrolled in inservice degree programs

8.5 Teachers' evaluation of the usefulness of inservice training programs in enhancing their pedagogical knowledge 
8.6 Teachers' evaluation of the usefulness of other professional training in enhancing their pedagogical

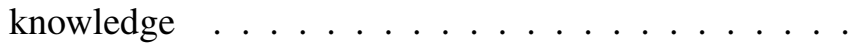

8.7 Teachers' evaluation of the usefulness of organized professional activities at the local/state and regional/ national levels . . . . . . . . . . . . . . . . .

8.8 Teachers' evaluation of the usefulness of organized professional activities at the school/department and district/county levels . . . . . . . . . . . .

8.9 Frequencies of teachers having non-organized professional activities . . . . . . . . . . . .

8.10 Teachers' evaluation of the usefulness of non-organized professional activities in enhancing their pedagogical knowledge . . . . . . . . . . . 200

8.11 How teachers use different sources to design the ways to represent new mathematics topics . . . . . . . . .

9.1 A summary of the main findings on the relative importance of different sources to the development of teachers' pedagogical knowledge . . . . . . . . . . . . . .

10.1 Singaporean students' performances in TIMSS mathematics studies from 1995 to 2011 . . . . . . . . . . . . . .

10.2 Numbers of students, teachers, and mathematics teachers in the six Singaporean schools . . . . . . . . . 230

10.3 Selection of teachers for classroom observation in the Singapore study . . . . . . . . . . .

10.4 Classes observed in the Singapore study . . . . . . . .

10.5 Results on how Singaporean teachers gave different evaluations on the contribution of various sources to the development of their knowledge of textbooks . . . . . . . . . . . . . .

10.6 Results of logistic regression on the data about the contribution of different sources to the Singaporean teachers' knowledge of textbooks 
10.7 Distributions of the numbers of the Singaporean teachers among the three groups giving different evaluations of the contribution of the source "experience as school students" to their knowledge of textbooks . . . . . . . . . . . . .

10.8 Sources of Singaporean teachers' knowledge of textbooks identified during the interview . . . . . . . . . 240

10.9 Results on how Singaporean teachers gave different evaluations on the contribution of various sources to the development of teachers' knowledge of using technology for teaching mathematics . . . . . . . .

10.10 Results of logistic regression on the data about the contribution of different sources to Singaporean teachers' knowledge of technology . . . . . . . . . .

10.11 Sources of Singaporean teachers' knowledge of technology identified during the interview . . . . . . . . . .

10.12 Results on how Singaporean teachers gave different evaluations on the contribution of various sources to the development of their knowledge of using concrete materials/physical models for teaching mathematics . . . . . . . . . . . . . .

10.13 Results of logistic regression on the data about the contribution of different sources to Singaporean teachers' knowledge of concrete materials . . . . . . .

10.14 Sources of Singaporean teachers' knowledge of concrete materials identified during the interview . . . . . . . 248

10.15 Results of logistic regression on the data about the contribution of different sources to the Singaporean teachers' PCnK (binary logistic model)

10.16 Singaporean teachers' responses across the three groups to the questions of their developing PCnK from the source of "experience as student" . . . . . . . . .

10.17 Singaporean teachers' responses across the three groups to the questions of their developing PCnK from the source of "preservice training" . . . . . . . . . . 
10.18 Sources of Singaporean teachers' PCnK identified during the interview . . . . . . . . . . . .

10.19 Results on how Singaporean teachers gave different evaluations on the contribution of various sources to the development of their PIK . . . . . . . .

10.20 Results of logistic regression on the data about the contribution of different sources to the Singaporean teachers' PIK . . . . . . . . . . . . . . .

10.21 Sources of Singaporean teachers' PIK identified during the interview . . . . . . . . . . . .

10.22 A summary of the main findings on the relative importance of different sources to the development of Singaporean teachers' pedagogical knowledge . . . . . . . . .

11.1 Comparison of the contribution of different sources to the development of teachers' curricular knowledge in the Chicago and Singapore studies

11.2 Comparison of teachers' average evaluation of the contribution of different sources to teachers' PCrK in the two studies . . . . . . . . . . . . . .

11.3 Comparison of the relative frequency (\%) of teachers identifying different sources for their PCnK about the teaching of specific mathematics contents . . . . .

11.4 Comparison of teachers' evaluations of the contribution of different sources to teachers' PCnK . . . . . . . . 265

11.5 Comparison of the contribution of different sources to teachers' PIK in Chicago and Singapore . . . . . . .

11.6 Comparison of teachers' average evaluation of the contribution of different sources to teachers' PIK in Chicago and Singapore . . . . . . . . . . . .

11.7 Differences about the importance of each source to the development of pedagogical knowledge among the teachers of three groups in Chicago (C) and Singapore $(\mathrm{S}) \ldots \ldots \ldots \ldots$

11.8 An overview of the results of the Chicago (CHA) and Singapore (SING) studies 
1E.1 Distribution of teachers by gender and school . . . . . 295

1E.2 Distribution of teachers by age and school . . . . . . 295

1E.3 Distribution of teachers by highest educational degree and school . . . . . . . . . . . . . . . . 296

1E.4 Distribution of the majors and minors of the degrees teachers earned . . . . . . . . . . . . . 296

1E.5 Distribution of teachers with different lengths of experiences of teaching mathematics . . . . . . . . . . 296

1F.1 Logistic regression on the data about the contribution of different sources to teachers' knowledge of textbooks . . . . . . . . . . . . . . .

1F.2 Logistic regression on the data about the contribution of different sources to teachers' knowledge of technology . . . . . . . . . . . . . 300

1F.3 Logistic regression on the data about the contribution of different sources to teachers' knowledge of concrete materials

1F.4 Logistic regression on the data about the contribution of different sources to teachers' PIK . . . . . . . . . .

1F.5 Logistic regression on the data about the frequencies of different sources teachers used to design the way to represent new mathematics topics . . . . . . . .

1F.6 Logistic regression on the data about the contribution of different sources to teachers' PCnK . . . . . . . . .

2A.1 Numbers of full-time and contract teachers in the six secondary schools in Singapore . . . . . . . . . 305

2A.2 Numbers of male and female teachers in the six secondary schools in Singapore . . . . . . . . . . . . 305

2A.3 Distribution of the teachers by age in the six secondary schools in Singapore . . . . . . . . . . . . . 306

2A.4 Academic qualifications of the teachers in the six secondary schools in Singapore . . . . . . . . . . . 306

2A.5 Distribution of the teachers according to their years of teaching experience in the six secondary schools in Singapore . . . . . . . . . . . . . 
This page intentionally left blank 


\section{Focusing on the Growth of Teachers' Knowledge: An Introduction}

There is no doubt that, over the last few decades, general politicians, educational leaders, researchers, and practitioners have increasingly realized the crucial importance of teachers' knowledge in improving the quality of classroom teaching and learning. Accordingly, the issue of how teachers gain or develop their knowledge has also been a hot topic in educational research and on-going debate. Answering this issue calls for research-based evidences and sound knowledge for policy making and school practice in relation to teacher recruitment, teacher education, and teacher professional development.

This book presents two research studies focusing on how teachers develop their knowledge in the pedagogy of mathematics. The first study was conducted in the city of Chicago of the United States (hereafter called "the Chicago study") and the second one was conducted in Singapore (hereafter called "the Singapore study"). Both studies address the same research questions, but in different social, cultural, and educational contexts. The first question is, are there different sources for teachers to gain their pedagogical knowledge? And the second is, if the answer to the first question is "yes", then how do different sources contribute to the development of teachers' pedagogical knowledge?

The book consists of two main parts. Part I is devoted to the Chicago study in a relatively detailed way. It contains the following nine chapters.

Chapter 1 introduces the background, the significance, and the research questions of the study. 
Chapter 2 first presents some epistemological background about the concept of knowledge for the study, and then provides a relatively broad review of the literature in the field of teacher knowledge, which is divided around three major issues: what knowledge do teachers need, what knowledge do teachers have, and how do teachers develop their knowledge.

Chapter 3 establishes a conceptual framework to examine teachers' pedagogical knowledge and the possible different sources from which teachers develop their pedagogical knowledge.

Under the conceptual framework, teachers' pedagogical knowledge is further classified into three components, namely, pedagogical curricular knowledge (PCrK): knowledge of teaching materials and resources, including technology; pedagogical content knowledge (PCnK): knowledge of ways to represent mathematics concepts and procedures; and pedagogical instructional knowledge (PIK): knowledge of general teaching strategies and classroom organizational models.

Chapter 4 introduces the research design, instruments, and procedures used for collecting and analyzing the data, which is gathered through a questionnaire survey, classroom observation, and interviews from 77 mathematics teachers in three high-performing high schools, a stratified random sample from the 25 best high schools in the metropolitan area of Chicago.

Chapters 5, 6, and 7 report the core findings of the Chicago study. More specifically, Chapter 5 reports the results about how teachers develop their PCrK, Chapter 6 is about how teachers develop their PCnK, and Chapter 7 is about how teachers develop their PIK.

Chapter 8 reports other findings of the study, supplementing the three earlier chapters by looking at some other issues concerning the development of teachers' pedagogical knowledge. It looks at each specific source identified in the study and does not separate the general pedagogical knowledge into three different components.

Chapter 9 provides a summary of the Chicago study and its main conclusions. It also discusses the implications of the findings for teacher educators, school administrators, and teachers themselves on how to effectively pursue the growth of teachers' pedagogical knowledge. The chapter also offers suggestions for further research concerning the development of teacher knowledge. 
Part II of the book comprises Chapter 10 and Chapter 11. Chapter 10 presents the Singapore study, but in a more concise manner, given the fact that it is largely a replication of the Chicago study in terms of conceptualization and research methods. Accordingly, more emphasis of the writing is placed on the Singapore study's different social, cultural, and educational context compared with the Chicago study's. The Singapore study has a purpose of confirmation and comparison of the findings with the Chicago study. The data was collected from 73 mathematics teachers in six secondary schools, a stratified random sample from all of the 152 secondary schools in Singapore.

Chapter 11 juxtaposes the Singapore study with the Chicago one and compares the similarities and differences of the results as revealed in the two studies. Some concluding remarks are offered at the end of the chapter.

Both the Chicago and Singapore studies revealed that there are various sources from which teachers can develop their pedagogical knowledge. In particular, both studies consistently found that teachers' own teaching experience and reflection is the most important source for them to develop all the three components of pedagogical knowledge, and teachers' daily or informal exchanges with their colleagues is the second most important source for all the three components of their pedagogical knowledge. For the other sources, the studies revealed, to a greater or lesser degree, there exists different importance in teachers' developing one or more components of their pedagogical knowledge. In addition, the teachers in Chicago reported that preservice training was the least important source, while their Singapore counterparts viewed it as a secondarily important source, for the development of their pedagogical knowledge.

It should be pointed out that the Chicago study was originally completed as the author's doctoral thesis and, after translation into Chinese, first published in a book series by East China Normal University Press, Shanghai, China in 2003. As a researcher and the author, I was heartened to know that the book has had a positive impact on China's national policy about school-based teacher professional development, ${ }^{1}$ and was regarded

\footnotetext{
${ }^{1}$ See Jian Liu's comments on the Chinese edition of the Chicago study. A Study on the Development of Teachers' Pedagogical Knowledge (2nd edition, back cover), Shanghai: East China Normal University Press, 2013.
} 
by researchers, generously, as one of the most influential studies in this area ${ }^{2}$ being widely used as a university graduate course book. According to the information provided by Dr. Dongchen Zhao, it has been cited 833 times in China (source: www.cnki.net, as of 1 March 2014) including 100 doctoral theses but excluding citations in books. In consideration of the demand from the readers, the publisher has decided to publish the second edition of the book in Chinese. I am delighted that the English version of the Chicago study, of which much original integrity is kept with some necessary changes, together with a follow-up study, the Singapore study, is now published by Imperial College Press.

Although the studies presented in this book were conducted in Chicago and Singapore with focus on pedagogical knowledge of mathematics teachers, I hope that the book can be of value not only to readers in these two countries and mathematics educators who will naturally feel it easier to understand the relevant background of the studies, but also to any educational policy makers and researchers, teacher educators, school administrators and teachers, and graduate students who are interested in the theme of teachers' knowledge development. The reason is that the issue of how teachers gain their knowledge has general importance and communality in different countries and across different subject matters, and it is also internationally a common challenge to continuously improve teachers' professional knowledge.

Many people have offered me a lot of important help in conducting the Chicago and Singapore studies and in writing and publishing this book. For this, I am indebted to my professors, colleagues, research assistants, and friends, in particular, Zalman Usiskin, Robert Dreeben, John Craig, Kenneth Wong, Susan Stodolsky, John McConnell, Steve Victora, Lilane Koehn, Timothy Kanold, Kwai Ming Wa, David Witonsky, Alfred Estberg, Suzanne Levin, Eileen Fernández, Susan Chang, and Tad Waddington for the Chicago study, and Christina Cheong, Lee Peng Yee, Lionel PereiraMendoza, Kho Tek Hong, Cheong Peck Yoke, Teo Yin Nah, Yeo Jia Chyang, Yeo Jinguang Mathew, and Zhu Yan for the Singapore study.

\footnotetext{
${ }^{2}$ For example, see Zhang (2009).
} 
I am also indebted to all the school teachers, heads of mathematics departments, and administrators in Chicago and Singapore who participated or helped in various ways in the two studies, though because of the agreement for conducting the studies, their names cannot be listed in this book.

I must thank my wife Ellen and our daughters Jenny and Kate for their patience and sacrifice for supporting me to write this book. In addition, I wish to thank Alice Oven and Tasha D'Cruz of Imperial College Press for their highly professional service and help in publishing the book. I also wish to thank my colleagues at Southampton: Keith Jones, Jacky Lumby and Daniel Muijs for their helpful suggestions for this book.

Finally, I would like to express my gratitude to the University of Chicago School Mathematics Project Royalty Fund and the Academic Research Fund of the National Institute of Education, Nanyang Technological University for their sponsorship in grants for me to conduct the Chicago and Singapore studies, and to the University of Southampton and its Southampton Education School for providing a supportive academic environment for me to complete this book. Of course, I must say that I am entirely responsible for all the views expressed in the book.

\author{
Lianghuo Fan \\ University of Southampton \\ Southampton Education School \\ March 2014
}

